\title{
Study on Coordination of Air Pollution in Beijing, Tianjin and Hebei Based on Holistic Governance
}

\author{
$\mathrm{Xu}$ Yan \\ School of Public Administration \\ Tianjin University of Commerce \\ Tianjin, China 300134
}

\begin{abstract}
In recent years, the problem of air pollution control in Beijing-Tianjin-Hebei economic circle has been paid more and more attention by the government and the public. The air pollution in the region is becoming more and more serious, and the administrative barriers between the local governments are difficult to break. The difficulty of the problem and the complexity of administration have caused the difficulties in the process of policy making and policy implementation in the regional air pollution control. In the dilemma, holistic governance theory as an effective tool came into being, in addressing the regional policy formulation and implementation of the fragmentation caused by the problem solved. The coordination and integration promoted by the integrated governance provide the organizational structure, integration path and long-term mechanism for the intergovernmental cooperation in air pollution control in BeijingTianjin-Hebei economic circle.
\end{abstract}

Keywords-Integral governance;

Intergovernmental collaboration; Collaborative integration

\section{INTRODUCTION}

Holistic governance theory originated from the "holism", and holism is proposed by the French Durkheim, he in the 19th century the theory applied to sociological research methods. The holistic model, as an important research method of holism, has been widely used in the social sciences since the 21st century. In 2002, the famous British scholar Hicks and others really put forward the concept of holistic governance theory. Hicks believes that if the theory of holistic governance applied to government management, the Government needs to integrate part of the main three dimensions: First, horizontal or vertical level of integration, that is, the integration of government departments, the Government and the Government integration and integration between the central government and local government; secondly, the integration of functions within the government, this functional integration not only includes the integration of internal functions of a single local government agencies, but also the functional institutions of each other In other words, functional integration is the integration of two or more departments with similar functions in a government organization. It is also for the sake of a common public purpose that multiple departments of different local governments participate in the integration; Finally, the integration of public and private, that is, government departments and private enterprises or non-profit organizations to cooperate through contract outsourcing, privatization and mergers and other forms of cooperation in order to better carry out administrative management and service to the people [1]

The concept of holistic governance plays an irreplaceable role in inter-regional intergovernmental governance. First, the guiding purpose of holistic governance is consistent with the governance requirements for intergovernmental cooperation in inter-regional air pollution. The overall goal of governance is to reduce the contradictions and tensions between different policies by reducing the conflicts or duplications between different projects in order to achieve the full use of resources, to provide the public with the overall, Seamless service. At the same time, along with the continuous development of regional economy, more and more administrative affairs go beyond the traditional bureaucratic administrative division, making the regional policy in the formulation and implementation of fragmented situation, when the overall governance theory In response to the fragmentation of regional administrative affairs. The integration of the holistic governance theory can break the traditional barriers of regional administration to a greater extent, so that local governments can break the restriction of the departmentalism in dealing with the regional public affairs, and can truly build the resources and problemoriented benign Interactive intergovernmental cooperation. Secondly, the theoretical framework of holistic governance provides an effective path to the fragmentation of intergovernmental coordination of inter-regional air pollution. The characteristics of trans-regional air pollution have obvious externalities, which determines the problem that trans-regional air pollution can not be solved by the strength of a local government, and needs the coordination and cooperation among the relevant local governments. However, China's strict hierarchical administrative system determines the chaotic situation of fragmentation and multiple management of trans-regional air pollution control. In order to solve the problem of fragmentation of trans-regional air pollution control, the inter-governmental cooperation and resource integration advocated by the holistic theory provide an effective way to solve this problem. All in all, the theoretical framework of holistic governance provides an effective path for inter-governmental coordination of fragmentation of inter-regional air pollution. 


\section{The PRESENT SituATION OF LOCAL GOVERNMENT'S COOPERATIVE GOVERNANCE}

Beijing, Tianjin and Hebei is not simply the meaning of the three cities, but as the Beijing-Tianjin-Hebei economic zone is a regional concept of integrity. The region includes 11 prefecture-level cities in Beijing, Tianjin and Hebei, with an area of 216,000 square kilometers and a population of 110 million. Beijing-Tianjin-Hebei is the largest economic circle after the Yangtze River Delta and Pearl River Delta. Especially in recent years, haze frequently occurred, serious threat to the health of the public and hinder the further development of the economy, air pollution, regional cooperation and governance imminent, the air pollution in the region has become more and more serious, And as a cross-regional inter-governmental collaboration the latest and most effective governance tool - the overall application of governance and health.[2]

\section{A. Administrative Barriers Remain Serious}

Beijing-Tianjin-Hebei region of the three main differences between the administrative body is very obvious, Beijing as the capital of thousands of pet in one, holds the superior political capital and information resources, and Tianjin as one of the four municipalities, also enjoy A variety of administrative priorities and resource control, and Hebei as an ordinary province, its economic, cultural and educational aspects can not be comparable with the Beijing and Tianjin. Therefore, there is a big difference between the three administrative bodies, which makes the administrative cooperation between the three places more complicated. In the face of regional cooperation, there are some discrepancies in the discourse power, executive ability and ruling status among administrative subjects in the region. In the treatment of trans-regional air pollution, Beijing and Tianjin are densely populated, with the continuous development of industry and the city, industrial pollution, domestic exhaust and automobile exhaust and other pollutants generated a lot, resulting in a serious haze And other weather conditions, This makes the heavily polluting industries in Beijing and Tianjin began to shift to Hebei Province in an attempt to reduce the industrial burden of the two areas, while the economic and social development in Hebei is relatively backward, have to accept the expense of the environment at the expense of heavy industry. However, the Beijing-Tianjin-Hebei is a neighbor, and air pollution does not exist in the presence of barriers to the existence of administrative barriers, pollution sources can not really prevent the transfer of air pollution on the social life of Beijing and Tianjin, the atmosphere is mutual circulation ,However, the differences in the political and economic status between the three places have hindered the cooperation between the three places, which is a major obstacle to the development of regional economy.

\section{B. Air Pollution Continues to Increase}

The second industry of Hebei province in the BeijingTianjin-Hebei economic circle is much higher than that of the tertiary industry. The secondary industry and the tertiary industry of Tianjin are almost the same. Although the industrial transformation of Beijing is almost realized, But the surrounding suburbs or to the secondary industry, there is no fundamental to eliminate pollution sources, the economic circle of pollution is still no substantive change. On the other hand, the Beijing-Tianjin-Hebei region has always been rich in mineral resources, and heavy industry pollution is the key to air pollution in the region, in the industrial structure of Beijing, Tianjin, iron and steel industry has an important position in the industrial structure, In Hebei Province, the industrial output value accounted for one-third of the province's industrial output value, while the steel industry with high energy consumption, high emission and high pollution characteristics, is recognized as a major factor in air pollution, which resulted in the region The seriousness of air pollution and the difficulty of governance.

\section{THE DILEMMA OF INTERGOVERNMENTAL COOPERATION IN BEIJING, TIANJIN AND HEBEI}

\section{A. Fragmentation of Regional Policy Formulation}

First, there is a problem between central legislation and local regulations. Central environmental legislation comprehensive, regional environmental diversity is difficult to reflect. With the development of Beijing-Tianjin-Hebei regional economy and the complication of public affairs in recent years, the central government has enacted a lot of legislation to improve air pollution prevention and control in Beijing, Tianjin and Hebei, such as the Environmental Protection Law and the Air Pollution Control Law. , These laws for the Beijing-Tianjin-Hebei air pollution control provides a fundamental legal guarantee. However, because the central government and local government focus on legislation is different from the central government to stand in the perspective of common legislation, legislation has overall and macroscopic, and Beijing and Tianjin air pollution governance problems are diverse, With a regional and personalized, which resulted in the central legislation and local legislation discord. Second, there is a relative lack of coordination between the various localities in the region. The administrative legislation of Beijing, Tianjin and Hebei is the air pollution prevention and control measures which only focus on the actual situation in the administrative area. The smaller the coordination of the overall situation of the three regions, however, the negative externalities of air pollution determine the atmosphere Pollution is not a single administrative divisions can be resolved, is the need for Beijing and Tianjin as a whole, the overall planning to prevent pollution.

\section{B. Fragmentation of Regional Policy Implementation}

The implementation of regional policies is a process of implementing regional cooperation governance, but in reality, the implementation of policies is often compromised with the original intention of the introduction of the policy. In the process of air pollution control in Beijing, Tianjin and Hebei, on the one hand, there exists a separate administrative law enforcement system of local government for local protectionism and individual rationality, that is, the relevant local governments in Beijing, Tianjin and Hebei Air 
pollution control "in the sweep of the door", the interests of the game in the "prisoner's dilemma" governance situation, and the Beijing-Tianjin-Hebei air pollution control has become a "public tragedy" typical example; China's current political system is the traditional bureaucratic system, which determines the relevant administrative bodies in the Ziya River Basin water pollution control division of labor complex, the prevalence of specialized law enforcement, which in turn formed China's regional Law enforcement of the "multi-management" professional law enforcement in the Ziya River Basin water pollution control, would have been a holistic air pollution control, due to the implementation of its governance and the main body of a clear division of labor, although professional The division of labor cooperation to a certain extent, can improve the efficiency of law enforcement, but most of the law enforcement between the division of labor without cooperation, leading to law enforcement "fragmentation", destroyed the Beijing-TianjinHebei air pollution control holistic .

\section{THE INTEGRATED APPROACH TO THE SYNERGY OF Air Pollution In BEIJING, TIANJIN AND HeBEI}

\section{A. Improve Laws and Regulations, Improve the Integrity of Decision-making}

Beijing-Tianjin-Hebei air pollution control has been fragmentation of the situation, a very important reason is that China's existing laws and regulations are not yet mature, there are some shortcomings. First of all, in our country's central legislation, we should formulate the regional intergovernmental governance law, and make specific requirements and provisions, making the regional intergovernmental cooperation law to follow, and second, in the Beijing-Tianjin-Hebei administrative bodies should be mutual Cooperation, and clear each other's rights and obligations, administrative bodies enacted by the administrative regulations should have consistency and synergy, to avoid conflict and gaps.

\section{B. To Build a Synergistic Mechanism to Provide Regional Cooperation Security}

Cross-sectoral governance of the two major objectives is to cooperate and governance, through the realization of collaboration, and ultimately achieve the purpose of governance. Therefore, the inter-governmental coordination of air pollution in Beijing, Tianjin and Hebei needs to establish a synergistic mechanism. On the one hand, the Beijing-Tianjin-Hebei region needs to establish a security mechanism. If there is no regional interests of the existence of security agencies, local governments may be in the pursuit of local interests, it will affect the regional interests of the whole, only the establishment of the corresponding regional interests to protect institutions in order to allow local governments in the overall interests of radiation regulate themselves Local policies to control air pollution. On the other hand, there is a need to improve regional synergies. Local governments in Beijing, Tianjin and Hebei have authorized a trans-regional cooperation agency to develop and plan specific measures for the control of air pollution in the region. Under the guidance of this measure, the local governments will adopt a localized governance plan in the light of the actual situation of their respective administrative regions. This avoids the administrative bodies of the fragmented, separate situation, there are benefits to promote coordination and cooperation between the Government.

\section{Improve the Supervision System to Ensure Effective Regional Governance}

Inter-regional governance of air pollution, which involves a number of administrative bodies and administrative departments, which makes the governance process is complex and there is variability. The norms of the behavior of various administrative bodies need to have a professional supervision and evaluation of the monitoring mechanism to be more effective implementation. On the one hand, it is necessary to strengthen the supervision of the external agencies and the public on the process and results of the air pollution cooperation in Beijing, Tianjin and Hebei. The economic differences between the administrative bodies of Beijing, Tianjin and Hebei are very big, each has its own local interests. In the process of regional cooperation in the control of air pollution, they can not fully guarantee that they will consciously feel the conflict between local interests and public interests. Safeguard the public interest. Therefore, only by strengthening the external oversight to ensure its more effective implementation of the cooperation between regions in order to achieve the public interest; the other hand, the administrative bodies should also be mutual supervision between the control of "free-rider" behavior and "Common to sad." In many cases, external agencies and the public are not aware of the cooperation and collaboration within the various administrative bodies. Only the various administrative bodies have a better understanding and understanding of policy-making and policy implementation.

\section{CONCLUSION}

Along with the continuous development of BeijingTianjin-Hebei economy, more and more air pollution control goes beyond the traditional administrative area, making the regional policy in the formulation and implementation of the fragmentation of the situation, when the overall good governance theory In response to the fragmentation of regional administrative affairs. Through the integration of the holistic governance theory, it can break the administrative barrier of Beijing, Tianjin and Hebei to a greater extent, and promote the local governments to jump out of the bureaucratic system when dealing with air pollution, regard the local governments in the region as a The integrity of the government, with the same administrative purposes, the pursuit of common interests, so as to fundamentally solving the problem of air pollution and promoting regional common development.

\section{REFERENCES}

[1] Perri 6, Diana Leat, Kimberly Seltzer and Gerry Stoker, Towards Holistic Governance: The New Peform Agenda, New York: Palgrave, 2002. 
[2] Zhu Guanglei, Zhang Chuanbin. Systematic perfection and fostering intergovernmental partnership - on the "counterpart support" system [J]

[3] Hu Jia. Towards holistic governance: the overall strategy of government reform and its applicability in China [J].

[4] List, Mirchandani, Turnquisteta.l. Modeling and analysis for hazardous materialstransportation: risk analysis [J]. Routing /Scheduling and Facility Location, 1991.25(2): 100-114.

[5] Hans, Palleeta.1. Accidents during marine transport of dangerous goods: distribution offatalities $[\mathrm{J}]$. Journal of loss prevention in the process industries, 1995.

[6] Zhu Ganwei. From New Public Administration to Holistic Governance [J]. ChineseAdministrative Management, 2008,10: 52-58.

[7] Journal of Central China Normal University (Humanities and Social Sciences), 2010,01: 11-15.

[8] Hu Xiangming, Tang Boyong. Holistic Governance: A New Paradigm of Public Administration [J].

[9] Cui Jing.The Study on the Integrative Governance Model of Transboundary Public Affairs of Regional Local Government: A Case Study of Beijing-Tianjin-Hebei Metropolitan Area [J] .Political Studies, 2012,02: 91-97.

[10] Ding Huang, Fang Kun.The Research on the Reform of Comprehensive Administrative Law Enforcement System Based on Holistic Governance [J] .Leadership Science Forum, 2016, 01: 5-17. 